\title{
Anaesthetic Management of Coexisting Preeclampsia and Paraganglioma in Pregnancy
}

\author{
Michelle Leanne Lim, Jacklyn Jialin Yek, Singara Selvan \\ Department of Anaesthesiology, KK Women's and Children's Hospital; 100 Bukit Timah Road, Singapore 229899.
}

\section{Corresponding Author:}

Dr Michelle Leanne Lim

Email: michelle.lim3@mohh.com.sg

This is an Open Access article distributed under the terms of the Creative Commons Attribution License (creativecommons.org/ licenses/by/3.0).

Received Accepted Published

August 18, 2019

November 28, 2019

January 5, 2020

\begin{abstract}
Background: We describe the peri-operative challenges and anaesthetic management of a 36-year-old woman diagnosed with functioning paraganglioma and pre-eclampsia on a background of chronic hypertension, presenting with a twin pregnancy after in-vitro fertilization. Due to its rarity, management is often based on case studies and expert opinion. Case Report: This patient presents both diagnostic and management challenge, and it highlights the importance of considering overlapping pathologies in a patient with resistant hypertension. Furthermore, management of preeclampsia and catecholaminesecreting tumors may contradict each other and hence demand a multidisciplinary approach with obstetricians, endocrinologists and intensivists. Conclusion: The primary goals of catecholamine-secreting tumors and preeclampsia in pregnancy are early diagnosis and avoiding anticipated sympathetic surge.
\end{abstract}

Keywords: Catecholamines, Hypertension, Paraganglioma, Pre-Eclampsia, Pregnancy.

\section{Introduction}

Incidence of pheochromocytoma or paraganglioma during pregnancy is estimated to occur in $0.007 \%$ of all pregnancies [1]. Due to its rarity, management is often inferred from case studies and expert opinion. We describe the peri-operative challenges and anaesthetic management of a 36-year-old woman diagnosed with functioning paraganglioma and pre-eclampsia on a background of chronic hypertension, presenting with a twin pregnancy after in-vitro fertilization. This patient presents both a diagnostic and management challenge, and highlights the importance of considering overlapping pathologies in a patient with resistant hypertension. This is the first described early presentation of concomitant paraganglioma and preeclampsia in a parturient and highlights how its diagnosis and subsequent multidisciplinary management with obstetricians, endocrinologists and intensivists resulted in favourable maternal and fetal outcome. We also describe our anaesthetic technique and anticipated anesthetic complications as well as how we addressed them.

\section{Case Report}

A 36-year-old Chinese primigravida, presented at 10 weeks gestational age on routine antenatal visit, after successful in-vitro fertilization. She had a 10 -year history of hypertension on oral nifedipine LA $60 \mathrm{mg}$ bd. Ultrasound Doppler revealed a viable twin pregnancy. At gestational week 12 , she presented with hypertensive crisis of 180/94 mmHg, episodic headaches and sinus tachycardia of 120 beats per minute. Thyroid function tests were normal. Ultrasound kidney was unremarkable. A 2-D echocardiogram revealed a left ventricular ejection fraction of $70-75 \%$ with no valvulopathies.

A differential diagnosis of phaeochromocytoma was considered. 24-hour urine norepinephrine level was $796 \mathrm{nmol}$ [Normal $(\mathrm{N}): 89-473 \mathrm{nmol} / \mathrm{day}]$, dopamine $8450(\mathrm{~N}: 424-$ 
2612 nmol/day), metanephrine 1323 (N: 400-1500 nmol/day), normetanephrine 5378 (N: 6000-1900 nmol/day). A non-contrast abdominal MRI at gestational week 14 was unremarkable. The likely diagnosis of paraganglioma was suspected and she was followed up closely in the high risk maternalfetal clinic by the obstetrician and endocrinologist. She was also started on phenoxybenzamine $20 \mathrm{mg}$ twice daily. At gestational week 33, she was readmitted for uncontrolled hypertension. Investigations revealed elevated uric acid levels up to $777 \mathrm{umol} / \mathrm{L}$, urine total protein $6.1 \mathrm{~g} / \mathrm{L}(\mathrm{N}$ : 0.01-0.14 g/L) and a mild transaminitis suggestive of concomitant preeclampsia. PO labetalol 200 mg tds was started but she remained hypertensive with episodic headaches. Intravenous magnesium sulphate infusion was started at $1 \mathrm{~g}$ /hour. Decision was made for urgent caesarean section in view of impending eclampsia. Her height and weight was $150 \mathrm{~cm}$ and $75 \mathrm{~kg}$ respectively. Two $18 \mathrm{G}$ intravenous cannulas, and a $20 \mathrm{G}$ radial intra-arterial line was inserted pre-induction. Emergency medications were prepared including IV phentolamine and IV esmolol. Pre-induction blood pressure was 170/100 $\mathrm{mmHg}$ with a heart rate of 90 beats $/ \mathrm{min}$. She was given divided doses of esmolol $10 \mathrm{mg}$ to a total of $90 \mathrm{mg}$ to attain BP of $150 / 80 \mathrm{mmHg}$. IV magnesium sulphate $1 \mathrm{~g} /$ hour infusion was continued. A rapid sequence induction and cricoid pressure with thiopentone $375 \mathrm{mg}$, succinylcholine $100 \mathrm{mg}$ and IV atracurium $30 \mathrm{mg}$, target controlled infusion remifentanil was started at $4 \mathrm{ng} / \mathrm{ml}$, increased to $6 \mathrm{ng} / \mathrm{ml}$ during intubation, and maintained at $4 \mathrm{ng} /$ $\mathrm{ml}$ during the surgery. Airway was secured using C-MAC videolaryngoscope \#3 Mackintosh blade with a \#7.0 oral endotracheal tube. Anaesthesia was maintained on nitrous oxide:oxygen 50:50, and end-tidal sevoflurane concentration of $1.5 \%$.

Twins weighing $2.283 \mathrm{~kg}$ and $1.786 \mathrm{~kg}$ were delivered. Twin one was sent to neonatal intensive care unit for ventilatory support. Twin two was sent to special care nursery for monitoring due to low birth weight. Oxytocin (3 units) was then given as a slow bolus and continued as an oxytocin infusion of 30 units over 4 hours. Post-delivery, her systolic blood pressure dropped to 50-60 $\mathrm{mmHg}$. IV magnesium sulphate was temporarily discontinued. A total of $40 \mathrm{mg}$ of ephedrine and $1000 \mathrm{mcg}$ of phenylephrine was administered promptly to achieve MAP $>55 \mathrm{mmHg}$. Her BP subsequently responded to $1 \mathrm{~L}$ of gelafundin, maintaining systolic $100 \mathrm{mmHg}$. Neuromuscular blockade was reversed with neostigmine $2.5 \mathrm{mg}$ and atropine $0.9 \mathrm{mg}$. She was extubated awake and transferred to the intensive care unit for further monitoring. Post-operatively, she was continued on PO nifedipine LA $60 \mathrm{mg}$ twice daily, PO atenolol $25 \mathrm{mg}$, phenoxybenzamine $20 \mathrm{mg}$ twice daily and IV magnesium sulfate infusion for 24 hours. On $3^{\text {rd }}$ post-operative day, she was discharged from the intensive care unit.

\section{Discussion}

Pheochromocytomas and paraganglioma (PGL) are neuroendocrine tumors derived respectively, from adrenal chromaffin cells and extra-adrenal paranglia, and estimated to occur in $0.007 \%$ of all pregnancies. Overall maternal and fetal mortality is said to be $3.6 \%$ and $12 \%$ respectively [1]. Hypertension, gestational or chronic, occurs in $3.6 \%$ to $9.1 \%$ of pregnancies [2]. Particularly, this patient highlights the possibility of dual pathologies presenting in a parturient. Although Table 1 illustrates the differences between preeclampsia (PE) and PGL in presentation, often these symptoms are variable and non-specific hence demanding a high clinical suspicion and low threshold to investigate. Undiagnosed catecholamine secreting tumors (CST) may have a detrimental outcome as management differs. While labetolol is a recommended first-line therapy for hypertension in parturients, oral labetolol has a 3:1 beta:alpha blockade and starting beta-blockade in a patient with CST could result in unopposed alpha-adrenergic receptor stimulation that could precipitate a hypertensive crisis. 
The management of BP in a parturient with CST requires a fine balance between adequate catecholamine blockade and maintaining uteroplacental perfusion. Alpha-blockade is typically first-line as norepinephrine is predominantly secreted and guided by Roizen criteria [3] to determine adequacy of alpha-blockade in nonpregnant patients. In a parturient, there is no known target blood pressure and hypotension may result in insufficient utero-placental perfusion. Conversely, hypertensive surges may compromise the uteroplacental circulation, leading to intrauterine growth regardation and fetal demise [4]. Compounded by preeclampsia which suggests abnormal placentation, impaired spiral arteries invasion and placental hypoperfusion, it is prudent to accept a higher target of $<150 / 100 \mathrm{mmHg}$ or $<$ $140 / 90 \mathrm{mmHg}$ if end-organ involvement is present [5]. Starting alpha-blockers has its own risks as drugs such as phenoxybenzamine can transfer across the placenta and accumulate in fetal blood. Newborns are at risk of respiratory depression and hypotension, and must be observed closely after delivery [6]. The definitive treatment for preeclampsia is the delivery of the fetus.

Furthermore, there are vast differences in patient management between PE and CST, and hence dual pathologies demand weighing the pros and cons of both. CSTs discovered in the first 24 weeks of gestation should be removed preferably by a laparascopic approach in the second trimester; whereas CSTs discovered in the third trimester should delay surgical excision till fetus is viable and able to be delivered, with the tumor being removed either immediately after delivery or at a later date [7]. Conversely, anti-hypertensive therapy and magnesium sulphate should be started for patients with severe $\mathrm{PE}$ as a temporizing measure, and the definitive treatment is delivery. In our patient where the PGL was not located, compounded by $\mathrm{PE}$, we recommend that management should be individualized based on the i) nature of the catecholamine-secreting tumour (CST),
Table 1: Comparison of diagnosis, management of preeclampsia versus paraganglioma.

\begin{tabular}{|c|c|c|}
\hline & Preeclampsia & $\begin{array}{l}\text { Paraganglioma / } \\
\text { Pheochromocytoma }\end{array}$ \\
\hline $\begin{array}{l}\text { Presenting } \\
\text { symptoms }\end{array}$ & $\begin{array}{l}\text { - Sustained hypertension } \\
\text { - Headaches in severe PE } \\
\text { - Abdominal pain } \\
\text { - Weight gain (fluid } \\
\text { retention), bipedal } \\
\text { edema, acute } \\
\text { pulmonary oedema }\end{array}$ & $\begin{array}{l}\text { - Paroxysmal hypertension } \\
\text { - Sweating, palpitations, } \\
\text { headache, flushing } \\
\text { - Weight loss } \\
\text { - Peripartum } \\
\text { cardiomyopathy } \\
\text { - Varied signs/symptoms } \\
\text { depending on catechola- } \\
\text { mines produced \& } \\
\text { secreted }\end{array}$ \\
\hline Onset & $\begin{array}{l}\text { - After } 20 \text { weeks of } \\
\text { gestation }\end{array}$ & - At any gestational phase \\
\hline Investigations & $\begin{array}{l}\text { - Proteinuria } \\
\text { - Thrombocytopenia } \\
\text { - Liver transaminitis }\end{array}$ & $\begin{array}{l}\text { - Increased urine } \\
\text { metanephrine, } \\
\text { normetanephrine } \\
\text { - Increased plasma } \\
\text { norepinephrine, } \\
\text { epinephrine, dopamine } \\
\text { - Episodic hyperglycaemia }\end{array}$ \\
\hline $\begin{array}{l}\text { Associated } \\
\text { signs/ } \\
\text { symptoms } \\
\text { that may } \\
\text { mimick the } \\
\text { other }\end{array}$ & $\begin{array}{l}\text { Elevated plasma or } \\
\text { urinary catecholamine } \\
\text { levels in severe PE }\end{array}$ & $\begin{array}{l}\text { - Renal impairment, } \\
\text { proteinuria }\end{array}$ \\
\hline $\begin{array}{l}\text { Initial } \\
\text { treatment }\end{array}$ & $\begin{array}{l}\text { - Direct vasodilators } \\
\text { (methyldopa labetolol } \\
\text { nifedipine) } \\
\text { - Combined alpha-beta } \\
\text { blockers (labetolol) } \\
\text { - Calcium channel } \\
\text { blocker (nifedipine) }\end{array}$ & $\begin{array}{l}\text { - } \alpha \text {-blockade } \\
\text { (phenoxybenzamine, } \\
\text { prazosin, doxazosin) }\end{array}$ \\
\hline
\end{tabular}

gestational age iii) patient's wishes; and undertaken jointly by a multidisciplinary team of obstetricians, endocrinologists and anaesthesiologists.

The use of spinal anaesthesia in LSCS to obtund sympathetic stimulation from pain during LSCS has been described in literature. However, our decision to proceed under general anaesthesia was in view of i) airway control in view of the potentially difficult airway in preeclampsia secondary to airway edema and ii) expected hemodynamic instability. Normalizing blood pressure, heart rate and restoring intravascular volume are the main targets in the pre-operative management of PGL [7] as patients on alphablockers are typically volume-deplete but with concomitant pre-eclampsia, judicious fluid administration is advisable to avoid precipitating acute pulmonary edema. Our anaesthetic goals are mainly to maintain hemodynamic stability. 
Intra-operative catecholamine surges should be anticipated and suppressed during laryngoscopy and tracheal intubation, surgical stimulation and fundal pressure. This should be performed by ensuring adequate depth of anaesthesia and use of drugs such as remifentanil infusion for quick titration to these stimulating events. Remifentanil is used in spite of its ability to cross the placenta as it is rapidly metabolized and redistributed in the fetus. Invasive intra-arterial cannulation is necessary for tight control of blood pressure. Large bore IV cannulation should be established before induction for fluid resuscitation if necessary.

Furthermore, drugs that may precipitate sympathetic crisis should be avoided. Particular to PGLs, avoidance of glucocorticoids may be essential as its administration may precipitate a catecholamine crisis as paragangliomas are postulated to be unlikely to secrete epinephrine, as the enzyme phenylethanolamine N-methyltransferase (PNMT), which converts norepinephrine to epinephrine, requires cortisol as a cofactor.

\section{Conclusion}

The primary goals of CST and PE in pregnancy are early diagnosis and avoidance of sympathetic surge. A multidisciplinary approach should be conducted and possibility of multiple pathologies should be considered especially in resistant hypertension.
Contributors: Lim ML and Yek JLJ conceived the presented idea, acquired and interpreted the data required as well as drafted and revised the manuscript in consultation with Selvan S. All authors have read and approved the final manuscript as well as provided critical feedback, discussed and are accountable for all aspects of the final manuscript in ensuring its accuracy and integrity are appropriately investigated and resolved.

Funding: None; Competing interests: None stated.

\section{References}

1. Wing LA, Conaglen JV, Meyer-Rochow GY, Elston MS. Paraganglioma in pregnancy: A case series and review of the literature. The Journal of Clinical Endocrinology \& Metabolism. 2015;100(8):3202-3209.

2. Roberts CL, Ford JB, Algert CS, Antonsen S, Chalmers J, Cnattingius S, et al. Population-based trends in pregnancy hypertension and pre-eclampsia: an international comparative study. BMJ Open. 2011;1(1):e000101.

3. Roizen MF, Horrigan RW, Koike M, Eger IE, 2nd, Mulroy MF, Frazer B, et al. A prospective randomized trial of four anesthetic techniques for resection of pheochromocytoma. Anesthesiology. 1982;57:A43.

4. van der Weerd $\mathrm{K}$, van Noord C, Loeve M, Knapen MFCM, Visser W, de Herder WW, et al. Pheochromocytoma in pregnancy: case series and review of literature. Eur J Endocrinol. 2017;177 (2):R49-R58.

5. NICE Guideline 107: hypertension in pregnancy. Available at: www.nice.org.uk/ guidance/CG107. August 2010. Accessed on August 18, 2019.

6. Santeiro ML, Stromquist C, Wyble L. Phenoxybenzamine placental transfer during the third trimester. Ann Pharmacother. 1996;30(11):1249-1251.

7. Lenders JW. Pheochromocytoma and pregnancy: a deceptive connection. Eur J Endocrinol. 2012;166:143150 . 